\title{
Variations
}

Variations

Revue internationale de théorie critique

$17 \mid 2012$

Critique du travail

\section{Images dialectiques}

Présentation d'une nouvelle rubrique

\section{Lucia Sagradini}

\section{(2) OpenEdition}

Journals

\section{Édition électronique}

URL : http://journals.openedition.org/variations/437

DOI : $10.4000 /$ variations.437

ISSN : 1968-3960

Éditeur

Les amis de Variations

Référence électronique

Lucia Sagradini, «Images dialectiques », Variations [En ligne], 17 | 2012, mis en ligne le 15 octobre 2012, consulté le 19 avril 2019. URL : http://journals.openedition.org/variations/437 ; DOI : 10.4000/ variations. 437

Ce document a été généré automatiquement le 19 avril 2019.

Les ami•e•s de Variations 


\title{
Images dialectiques
}

Présentation d'une nouvelle rubrique

\author{
Lucia Sagradini
}

1 «Parce que c'était lui, parce que c'était moi », une histoire de pensée, une histoire d'invention est parfois une histoire d'amitié ou une histoire d'amour. Entre Walter Benjamin et Berthold Brecht, il y eut de l'amitié, de l'échange et un foisonnement d'idées, même si, loin du récit mythique évoquant le lien de La Boétie et de Montaigne, il y avait aussi des écarts, des frottements et des tensions. Cependant, l'amitié était là, et elle se retrouve aussi dans les résonances qu'entretiennent le travail de Benjamin sur les images dialectiques et celui de Brecht sur les images dans son Kriegsjournal.

2 Ainsi le fil de l'amitié se retrouve autour de la question des images. L'idée phare de Benjamin peut être comprise comme le surgissement potentiel d'images venant du passé et à tout moment actualisables, des images portant autant d'expériences de la liberté que l'histoire tait après les avoir écartées. Brecht aura une correspondance au propre et au figuré avec Benjamin. Non seulement ils s'écrivent, mais ils travaillent aussi la question des images et par ricochet celle de la figurabilité.

Alors que le nazisme s'abat sur l'Allemagne et s'étend sur l'Europe, Brecht décide de passer par une élaboration par l'image pour saisir et souligner le monde halluciné dans lequel se déroule le cauchemar et la barbarie que représente le nazisme. Par le rapprochement de l'image et de la légende dans son Kriegsjournal, j'ai envie de dire un Schriftbild, il tient un journal sur les temps qu'il traverse et qui le traversent.

4 Il s'agit tout à la fois de dégager un sens qui semble caché par une figure singulière et inusuelle que de laisser la place à une forme qui s'échappe à la ratio. Pour saisir la barbarie des temps, Brecht cherche une forme atypique et marginale, inscrite sur un support à la fois porteur d'événements que d'intime, le journal. L'image en tant que Schriftbild, est l'émergence d'une figurabilité qui touche à l'inconscient, car la barbarie est aussi un temps où la raison s'effondre et où il devient nécessaire et vital de saisir les rouages obscurs que la ratio ne parvient pas à saisir.

5 Le Kriegsjournal est ainsi le moyen pour saisir l'insaisissable, l'infigurable, le passage par l'image légendée permet alors tous les rapprochements, toutes les associations d'idées et 
de formes, les raccourcis et les ellipses, mais également toutes les critiques, les dévoilements, par la mise en scène ou le simulacre, l'humour noir ou le désespoir, les formes de la guerre et de la mort peuvent être appréhendés.

Il me semble que le travail de Brecht est aussi à mettre en relation avec celui de Charlotte Beradt, Rêver sous le IIIe Reich, aux éditions Payot, qui lie cette nécessité de laisser une place à l'inconscient pour comprendre le IIIe Reich et ce qui est en train d'avoir lieu. Des intellectuels qui, à la suite de Benjamin, comprennent que comprendre une crise et une rupture civilisationnelle passe par un regard sur le versant inconscient pour pouvoir ramener du sens à ce qui est en dehors du sens. Par l'image se réalise aussi la tentative de cerner le danger. Message premier délivré par Benjamin, se saisir des images venant du passé et aussi se tenir en état d'alerte.

7 Aujourd'hui, les temps diffèrent, certes, mais une crise sans précédant s'abat sur nous. Les temps sont menaçants et hélas, l'alliance de la social-démocratie et de la droite dans son spectre le plus large (chrétienne ou extrême) ne nous apportera ni les réponses adéquates ni les garde-fous pour y faire face. Un temps où la présence des loups garous se fait sentir, sans encore être visible dans notre propre maison. La situation politique européenne passe aujourd'hui par des véhicules qui ne sont pas toujours conscients.

8 C'est ainsi la dureté des temps qui nous pousse à ouvrir cette nouvelle rubrique d'images dialectiques. Une rubrique où il s'agit de présenter une ou deux images légendées par numéro de Variations; des Schriftbild où l'auteur.e est libre d'envisager et de créer des relations dialectiques qu'il/elle pense être en jeu dans le réel et qui pourtant sont occultées. Un travail de visibilité donc. Pour que le cauchemar puisse prendre forme ou pour permettre à l'espérance d'être transmise. L'état d'alerte est bien donné.

\section{INDEX}

Mots-clés : critique du travail, correspondance, artistes, socialisme vert, travailleurs culturels, Wertkritik, Gorz André, dialogue, Vincent Jean-Marie, écologie, modèles alternatifs, Marx Karl, penser le Capital, ethos du travail, Eglise Orthodoxe, salariat, domination

\section{AUTEUR}

\section{LUCIA SAGRADINI}

Docteur en sociologie de l'Université de Caen CMH-CNRS, postdoctorante à l'UQAM et coordinatrice de Multitudes (2009-2011). Membre du comité de rédaction de Variations. 